NIST GCR 15-1008

\title{
NIST Disaster and Failure Studies Data Repository: The Chile Earthquake Database - Ground Motion and Building Performance Data from the 2010 Chile Earthquake - User Manual
}

Ann Christine Catlin Santiago Pujol 
NIST GCR 15-1008

\section{NIST Disaster and Failure Studies Data Repository: The Chile Earthquake Database - Ground Motion and Building Performance Data from the 2010 Chile Earthquake - User Manual}

Prepared for

Long Phan

Engineering Laboratory National Institute of Standards and Technology Gaithersburg, MD

By

Ann Christine Catlin

Santiago Pujol Purdue University

This publication is available free of charge from: http://dx.doi.org/10.6028/NIST.GCR.15-1008

December 2015

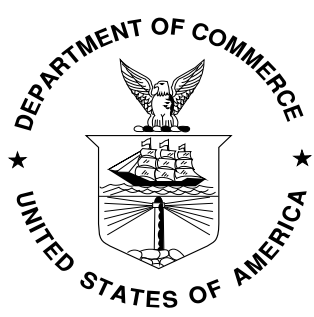

U.S. Department of Commerce Penny Pritzker, Secretary 


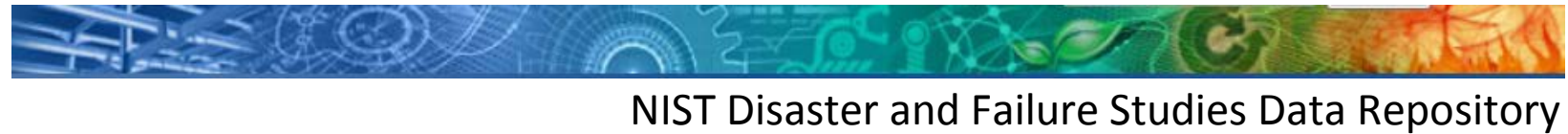

NIST Disaster and Failure Studies Data Repository

\section{The Chile Earthquake Database}

Ground Motion and Building Performance Data from the 2010 Chile Earthquake

\section{User Manual}




\section{TABLE OF CONTENTS}

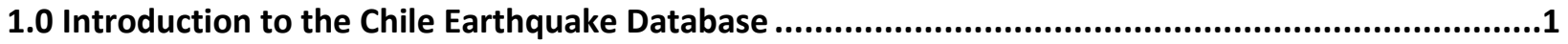

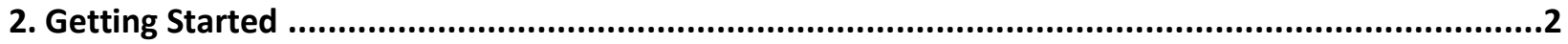

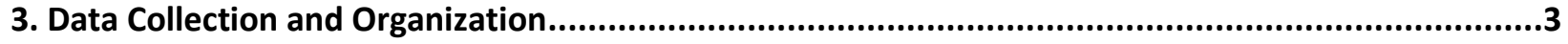

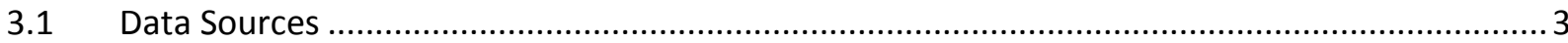

3.2 Information Model, Data Files and Keywords .................................................................. 4

4.1 Navigate, Search, Discover and Download Using "Dataviews" ............................................. 11

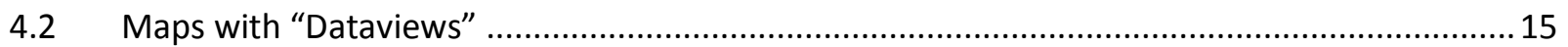

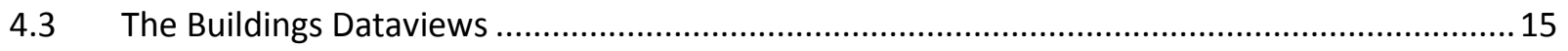

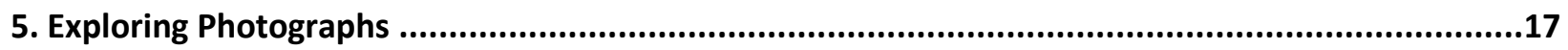

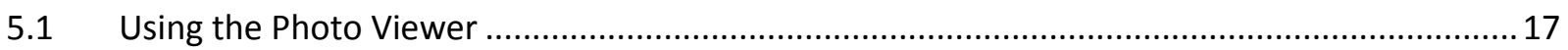

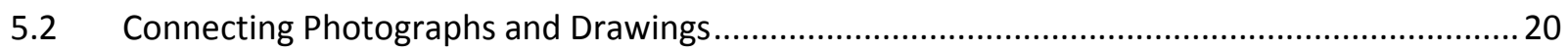

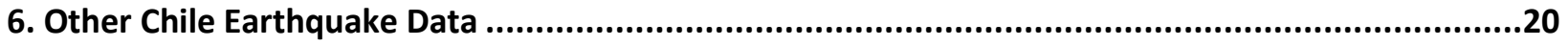

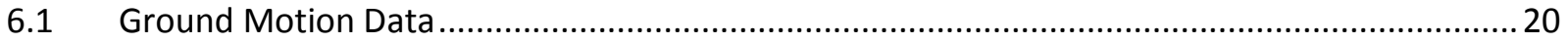

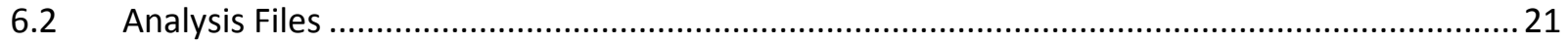

7. Data Preservation, Longevity and the HUBzero Technology ...................................................21 


\subsection{Introduction to the Chile Earthquake Database}

For decades, Chile has used building codes similar to those used in the United States. The 2010 earthquake in the Maule region of Chile caused severe damage to buildings which were designed based on the Chilean codes. To understand the implications of the observed failures in Maule for construction in the United States, it was essential to undertake a methodical study of the buildings that failed and compare them to similar buildings that did not fail.

Motivated by the need to understand structural failures in Maule, a number of organizations in the United States sent reconnaissance teams to collect comprehensive information related to structural performance, infrastructure performance and ground failures. Spatial distribution of damage using GPS technology was also of importance, as was the collection of ground motion data. In order to preserve the information collected by these teams and to make it available to a broader audience, the creation of an open data repository was deemed essential. The Chile Earthquake Database was created to serve this need.

The principal target audiences of the Chile Earthquake Database are structural and geotechnical engineers (in academia and in practice), standards organizations, building code committees and contractors who are best able to interpret the structural drawings, crack maps, photographs, material properties and soil reports which are contained in the Database. This content can be used to formulate hypotheses about the causes of structural damage in a format that can lead to changes in the construction and design practices used in Chile and, if necessary, the United States.

The Chile Database is designed to support exploration of 1) tabular data about structures, and 2) the collection of repository files that include photographs and other reconnaissance data files such as drawings. Users of the Chile Database are able to:

- explore photographic evidence of damage caused by the Maule Earthquake

- explore geotechnical and ground motion information from the Maule Earthquake

- search for entries associated with tags from a list of keywords

- associate photographs and performance data with building information, ranging from location and number of stories to seismic vulnerability indices such as the ratio of wall area to total floor area - where such data is available

- associate damage information and information on recorded ground motion

- correlate level of damage and structural properties

- explore and export data in a variety of formats including text, KMZ and KML (for Google Earth software) and SHP (for ESRI software)

- download full-resolution photographs, one at a time or in groups

- download drawings, mathematical models and reports for selected building structures

- compare damage caused by the 2010 Maule Earthquake and the 1985 Valparaiso Earthquake (where applicable)

- $\quad$ sort and select relevant information using multiple filters 


\section{Getting Started}

The Disaster and Failure Studies Program (DFSP) within the NIST Engineering Laboratory provides for the establishment of teams to assess building and infrastructure performance and emergency response and evacuation procedures in the wake of disaster and failure events that have resulted in substantial loss of life or posed significant potential of a substantial loss of life. Objectives of DFSP studies may include establishing the likely technical factors responsible for the damage, failure, and/or successful performance of buildings and infrastructure in the aftermath of a disaster or failure event, as well as determining the procedures and practices that were used in the design, construction, operation, and maintenance of the buildings and infrastructure.

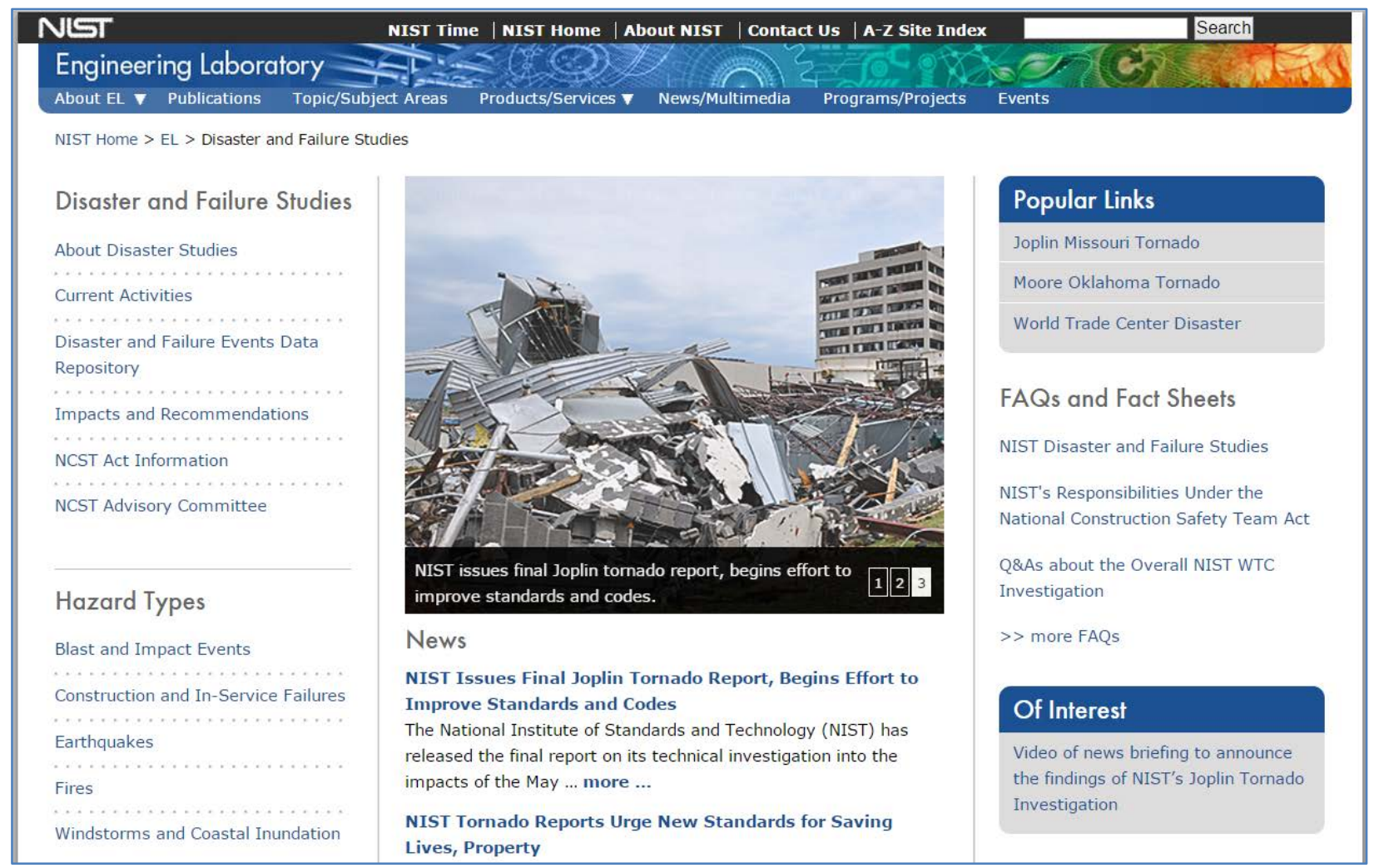

Figure 1 Web site of the Disaster and Failure Studies Program at NIST.

The DFSP is also creating databases to support the preservation and exploration of data collected from disaster events. The goal is to make unrestricted reconnaissance data from key disaster events publically accessible from a NIST Disaster and Failure Studies HUB.

The HUB can be reached from the DFSP web site at http://www.nist.gov/el/disasterstudies (Figure 1) where users can select the link XXXX under Popular Links to access the homepage of the NIST Disaster and Failure Studies HUB (Figure 2). Each of the disaster databases established by NIST has its own "landing page" which describes the disaster event and provides links to exploration tools for tabular data and repository files collected by reconnaissance teams. The link 2010 Chile earthquake on the NIST disaster databases homepage directs users to the Chile Earthquake Database landing page. 
Section 3 of this User Manual describes the collection and organization of the Chile earthquake reconnaissance data. Sections 4 through 6 provide a user guide for viewing, searching and exploring the data through tabular and photo viewers. Section 7 discusses data preservation on the HUB.
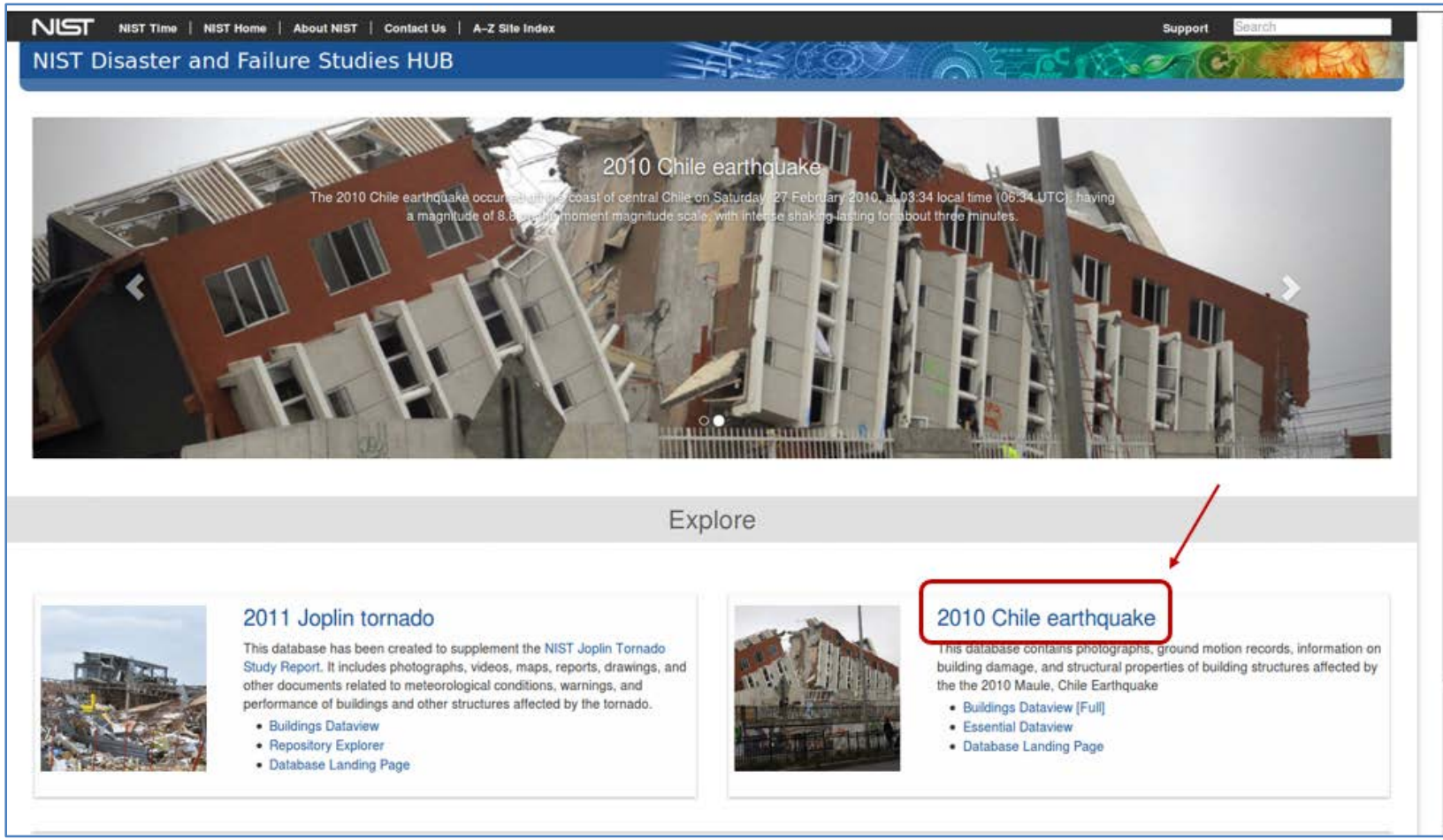

Figure 2 Homepage of the publicly available Disaster and Failure Studies HUB, which gives users access to disaster databases established by NIST for the preservation and exploration of reconnaissance data.

\section{Data Collection and Organization}

\subsection{Data Sources}

The Chile Earthquake database stores data for 273 building structures with nearly 25,000 photographs in the database repository. Data was obtained from the following sources:

Earthquake Engineering Research Institute (EERI)

National Institute of Standards and Technology (NIST)

Applied Technology Council (ATC)

L.A. Tall-Building Council (LATBC)

Purdue University

Penn State University

NSF RAPID-Program Team (Led by J. Moehle and F. Medina)

Degenkolb Consulting Structural Engineers

Chilean Researchers

BFP Engineers Inc.

Use permissions were collected by the Applied Technology Council (ATC) and Purdue University. Data is made available with the following disclaimer: 
Substantial effort has been made to obtain permissions for all copyright-protected images, drawings, text and figures. Materials available in the repository that do not have a copyright attribution may nonetheless be protected by copyrights owned by private individuals or organizations, and may be subject to restrictions on use. Where known, the copyright owner is identified with the image. You may want to obtain legal advice prior to further dissemination.

\subsection{Information Model, Data Files and Keywords}

Five categories of tabular data were collected in the Chile Database for two earthquakes, Valparaiso (1985) and Maule (2010). Data in these categories were identified as relevant parameters for organizing and classifying field observations on seismic performance. The categories are as follows:

Buildings: contains information on geometric and structural properties of buildings that were part of the reconnaissance effort. The Chile Database contains information from 273 buildings. Of these, 179 buildings were surveyed in 1985 (De La Llera, et al.), and 131 buildings were surveyed in 2010.

Earthquake Damage: contains information on the damage caused in each building. This information includes: photos, crack maps, a damage index, and information on the usability of the structure after the earthquake. Since the Chile Database contains information on two earthquakes, damage data is identified by earthquake.

Earthquake Information: describes the location and time of each earthquake.

Station Information: contains data from records obtained at strong-motion stations operating in Chile in 1985 and 2010. Key information is given for each station including type of soil (if known), peak ground acceleration (PGA), peak ground velocity (PGV), network, coordinates, location within housing structure (if applicable), and orientation.

Data Sources: lists the sources (references and individuals) providing information for the database.

In addition, reconnaissance data files are organized into a repository and tagged with essential information that associate the file to buildings, and can be used for search and exploration of the files by users. General drawings, typical floor drawings, general files and analysis files are all tagged with the building ID, source ID and identified for varying file types. Analysis files are also accompanied by a ReadMe file. The ground motion record files are tagged with the earthquake name, station ID and source ID and are identified for varying file types.

A collection of 23 keywords was developed for tagging photographs, these are listed in Table 1 . The keywords include labels used by members of reconnaissance teams to identify structural elements in drawings and crack maps. These keyword labels also appear in drawings (when available) to specify the location of the structural elements. Users can search for photographs in the Photo Viewer (described in Section 5) using one or more keywords.

Table 1 Keywords for searching photographs in the Chile Earthquake database

\begin{tabular}{|c|l|}
\hline Keyword number & Keywords for tagging and searching photographs \\
\hline 1 & Building \\
\hline
\end{tabular}




\begin{tabular}{|l|l|}
\hline 2 & Building Elevation \\
\hline 3 & Surroundings \\
\hline 4 & Nonstructural \\
\hline 5 & Reinforced Concrete \\
\hline 6 & Precast Concrete \\
\hline 7 & Steel \\
\hline 8 & Wood \\
\hline 9 & Masonry \\
\hline 10 & Coupling Beam \\
\hline 11 & Truss \\
\hline 12 & Column \\
\hline 13 & Wall \\
\hline 14 & Slab \\
\hline 15 & Beam \\
\hline 16 & Stairs \\
\hline 17 & Boundary Zone \\
\hline 18 & Tie \\
\hline 19 & Bar Splice \\
\hline 20 & Discontinuous Bar \\
\hline 21 & Wall Buckling \\
\hline 22 & Bar Buckling \\
\hline 23 & Bar Fracture \\
\hline
\end{tabular}

Data fields collected for strong motion are shown in Table 2.

Table 2 Data fields for strong motion

\begin{tabular}{|c|l|}
\hline $\begin{array}{c}\text { Column } \\
\text { Number }\end{array}$ & Data collected for strong motion and presented in the strong motion dataview \\
\hline 1 & Station ID \\
\hline 2 & Station Name* \\
\hline 3 & Station Code*** \\
\hline 4 & Earthquake Name \\
\hline 5 & Station Location*** \\
\hline 6 & Latitude of Station* \\
\hline 7 & Longitude of Station* \\
\hline 8 & Name of Network Maintaining the Station \\
\hline 9 & Instrument Location (in the structure housing it)* \\
\hline 10 & Structure Type (this refers again to the housing structure) \\
\hline 11 & Instrument Type* \\
\hline 12 & Site Description* \\
\hline 13 & Azimuth of Instrument Direction 1 \\
\hline 14 & Azimuth of Instrument Direction 2 \\
\hline 15 & Maximum Horizontal Peak Ground Acceleration \\
\hline 16 & Peak Ground Acceleration in Direction 1* \\
\hline 17 & Peak Ground Acceleration in Direction 2* \\
\hline
\end{tabular}




\begin{tabular}{|c|c|}
\hline 18 & Peak Ground Acceleration in Vertical Acceleration* \\
\hline 19 & Maximum Horizontal Peak Ground Velocity \\
\hline 20 & Peak Ground Velocity in Direction 1* \\
\hline 21 & Peak Ground Velocity in Direction 2* \\
\hline 22 & Acceleration Records* \\
\hline 23 & Name of the Person Entering the Information for each Station \\
\hline 24 & Comments \\
\hline 25 & Sources \\
\hline
\end{tabular}

rmation as reported by the person issuing the record

** The identifier usually coincides with the name of the city where the instrument was located.

The vast majority of engineered buildings in Chile have abundant reinforced concrete structures a) serving as partitions, and b) resisting lateral and gravity loads. These walls can be as thin as 8 inches in buildings reaching 10 to 20 stories in height. For this reason, the database concentrates on this type of structure. Concentrating on a single structural system allowed for a dramatic reduction in the number of parameters needed to describe a given structure.

A total of 108 parameters (or data elements) were identified to describe a structure and the ground motion affecting the structure. The parameters and definitions are supported by information provided by practitioners and academicians, and also from work done in the 1980 s by Riddell et al. ${ }^{1}$ and Global Earthquake Model (GEM) ${ }^{2}$. The chosen parameters range from peak ground velocity recorded at the closest strong motion station to ratio of total cross-sectional area of columns to typical floor area. The complete list of parameters is provided in Table 3.

Dataviewers for the Chile earthquake data (described in Section 4) offer "full" and "essential" views. The "full" building view contains a column for each of the parameters for every building - this dataview is sparse since most of the columns do not have parameter values for many buildings. (Table 3 ). The "essential" building view contains a subset of the parameters from the "full" view - this subset includes fields which were available for most buildings. (Table 4).

Notes for Tables 3 and 4 are as follows:

First Story: first story in which more than half the story height is above ground level

Units: SI

Italicized fields are related to a single earthquake.

Table 3 Complete list of data fields defined and collected for buildings in the Chile Database. The data appears in the "full" building data dataview with these column numbers.

\begin{tabular}{|l|l|}
\hline \multicolumn{1}{|c|}{$\begin{array}{c}\text { Column } \\
\text { Number }\end{array}$} & Data collected for buildings and displayed in the Full Building Data dataview \\
\hline & General Building and Site Information \\
\hline $1^{*}$ & Structure ID \\
\hline 2 & Building Name \\
\hline
\end{tabular}

${ }^{1}$ Riddell, R., Wood, S.L., and de la Llera, J.C. (1987). “The 1985 Chile Earthquake: Structural Characteristics and Damage Statistics for the Building Inventory in Vina del Mar," Civil Engineering Studies, Structural Research Series No. 534, University of Illinois, Urbana, IL, 265 p.

2 http://www.globalquakemodel.org/ 


\begin{tabular}{|c|c|}
\hline 3 & Owner \\
\hline 4 & Date or Range of Construction \\
\hline 5 & Occupancy (IBC Classification) \\
\hline 6 & Development ID \\
\hline \multirow[t]{2}{*}{7} & Development Name \\
\hline & Coordinates* (approximate coordinates of building plan centroid) \\
\hline $8^{*}$ & Latitude [decimal degrees] \\
\hline 9* & Longitude [decimal degrees] \\
\hline \multirow[t]{2}{*}{10} & Elevation $[\mathrm{m}]$ \\
\hline & Address \\
\hline $11^{*}$ & Street Name (required only if no coordinates are available) \\
\hline $12^{*}$ & Number (required only if no coordinates are available) \\
\hline $13^{*}$ & City \\
\hline $14^{*}$ & Postal Code (required only if no City name is available) \\
\hline 15 & Soil Type Class (NEHRP Standard) at Building Site \\
\hline 16 & Soil Type Class (Chilean Standard) at Building Site \\
\hline 17 & Building Site Description \\
\hline 18 & Source of Site Description \\
\hline 19 & Closest Ground Motion Recording Station ID \\
\hline \multirow[t]{2}{*}{20} & Distance to Closest Recording Station [km] \\
\hline & Building Information on Height and Shape \\
\hline $21^{*}$ & Total Number of Stories above Ground \\
\hline 22 & Number of Stories below Ground \\
\hline 23 & Total Floor Area (including All Floors and Basements) [m^2] \\
\hline 24 & Total Height above Ground [m] \\
\hline 25 & First-Story Height $[\mathrm{m}]$ \\
\hline 26 & $\begin{array}{l}\text { Reference Story (first story above podium) (for buildings with no podium this is the } \\
\text { first story with a total height above ground exceeding half the inter-story height) }\end{array}$ \\
\hline 27 & Number of Stories above Reference Story +1 \\
\hline 28 & Total Floor Area for Reference Story and Stories above [m^2] \\
\hline \multirow[t]{2}{*}{29} & Total Height above Reference Story + Height of Reference Story [m] \\
\hline & Directions (Definitions) \\
\hline 30 & Approximate Azimuth of Longitudinal Building Direction [decimal degrees] \\
\hline 31 & Approximate Azimuth of Transverse Building Direction [decimal degrees] \\
\hline 32 & Typical Plan Shape (R: rectangular, L: L shape, O: Other) \\
\hline 33 & Building Aspect Ratio in Longitudinal Direction (above Base of Reference Story) \\
\hline \multirow[t]{2}{*}{34} & Building Aspect Ratio in Transverse Direction (above Base of Reference Story) \\
\hline & Building Structural Properties \\
\hline 35 & Vertical Force-Resisting System \\
\hline 36 & Lateral Force-Resisting System \\
\hline 37 & Foundation Type \\
\hline 38 & Type of Partitions \\
\hline 39 & Nominal Concrete Cube Strength [MPa] \\
\hline 40 & Nominal Yield Stress of Steel [MPa] \\
\hline 41 & Measured Period of Vibration, Longitudinal Direction [s] \\
\hline 42 & Measured Period of Vibration, Transverse Direction [s] \\
\hline
\end{tabular}




\begin{tabular}{|c|c|}
\hline 43 & Calculated Period of Vibration, Longitudinal Direction [s] \\
\hline 44 & Calculated Period of Vibration, Transverse Direction [s] \\
\hline 45 & General Drawings \\
\hline 46 & Drawing of Typical Floor (above Base of Reference Story) \\
\hline 47 & Longitudinal Dimension \\
\hline 48 & Transverse Dimension \\
\hline \multirow[t]{2}{*}{49} & Typical Floor Area above Reference Story [m] \\
\hline & Total Cross-Sectional Wall Area (Ignoring Flanges) for the Reference Story [m^2] \\
\hline 50 & Longitudinal Dimension \\
\hline 51 & Transverse Dimension \\
\hline \multirow[t]{2}{*}{52} & Total Cross-Sectional Column Area for the Reference Story [m^2] \\
\hline & Ratio of Total Cross-Sectional Wall Area for Reference Story to Typical Floor Area \\
\hline 53 & Longitudinal Dimension \\
\hline \multirow[t]{2}{*}{54} & Transverse Dimension \\
\hline & $\begin{array}{l}\text { Ratio of Total Cross-Sectional Wall Area for Reference Story to Total Floor Area of } \\
\text { Reference Story and Stories above }\end{array}$ \\
\hline 55 & Longitudinal Dimension \\
\hline \multirow[t]{2}{*}{56} & Transverse Dimension \\
\hline & $\begin{array}{l}\text { Aspect Ratio of Dominant Walls (Ratio of Total Height above Base of Reference } \\
\text { Story to Length in Reference Story) }\end{array}$ \\
\hline 57 & Longitudinal Dimension \\
\hline 58 & Transverse Dimension \\
\hline 59 & $\begin{array}{l}\text { Ratio of Total Cross-Sectional Column Area for Reference Story to Typical Floor Area } \\
\text { above Reference Story }\end{array}$ \\
\hline \multirow[t]{2}{*}{60} & $\begin{array}{l}\text { Ratio of Total Cross-Sectional Column Area for Reference Story to Total Floor Area of } \\
\text { Reference Story and Stories above }\end{array}$ \\
\hline & $\underline{\text { Flags }}$ \\
\hline 61 & Splices at Base of Structure (0: none, 1: staggered, 2: not staggered) \\
\hline 62 & Reentrant Corners or Discontinuous Flanges in Walls (0: none, 1: present) \\
\hline 63 & Discontinuous Walls (0: none, 1 : present) \\
\hline 64 & Walls with T sections (0: none, 1 : present) \\
\hline 65 & Walls with L sections (0: none, 1: present) \\
\hline \multirow[t]{2}{*}{66} & Confining Reinforcement in Boundary Elements (0: none, 1: present) \\
\hline & Building Documentation \\
\hline 67 & General Files (Geotechnical Reports, Construction Records, etc.) \\
\hline $68^{*}$ & Photographs (format: JPG) \\
\hline 69 & Main Building Photograph (format: JPG) \\
\hline \multirow[t]{2}{*}{70} & $\begin{array}{l}\text { Input Files for Structural Analysis Software (each input file is to be associated with an } \\
\text { "readme" file with the same name and containing information on software name, } \\
\text { version, and analysis assumptions) }\end{array}$ \\
\hline & Earthquake Information \\
\hline 71* & Earthquake Name (e.g. Maule.Chile.2010 \& Valparaiso.Chile.1985) \\
\hline \multirow[t]{2}{*}{$72 *$} & Earthquake Date (UTC) \\
\hline & Information about Earthquake Damage** \\
\hline 73 & Was the building open or closed to public when first inspected (0: Open, 1: Closed) \\
\hline 74 & Tag assigned by local authorities (0: Green, 1: Yellow, 2: Red). \\
\hline
\end{tabular}




\begin{tabular}{|c|c|}
\hline 75 & Were clear structural failures or severe damage observed (0: No, 1: Yes) \\
\hline 76 & Path to photos showing structural failures or severe damage (if applicable) \\
\hline 77 & Were clear failures of nonstructural elements observed (0: No, 1: Yes) \\
\hline \multirow[t]{2}{*}{78} & Path to photos showing failures in nonstructural elements (if applicable) \\
\hline & Ground Motion Recording Station Information \\
\hline 79* & Station ID \\
\hline 80 & Recording Station Name \\
\hline 81 & Recording Station Code \\
\hline 82 & Recording Station Location \\
\hline 83* & Latitude of Recording Station [decimal degrees] \\
\hline $84 *$ & Longitude of Recording Station [decimal degrees] \\
\hline 85 & Recording Station Network \\
\hline 86 & Location of Accelerometer at Recording Station \\
\hline 87 & Type of Structure where Accelerometer was located \\
\hline 88 & Type of Accelerometer \\
\hline 89 & Recording Station Site Description \\
\hline 90 & Azimuth of Axis 1 for Accelerometer [decimal degrees] \\
\hline 91 & Azimuth of Axis 2 for Accelerometer [decimal degrees] \\
\hline 92 & Maximum Horizontal Peak Ground Acceleration [g] \\
\hline 93 & Peak Ground Acceleration along Axis 1 [g] \\
\hline 94 & Peak Ground Acceleration along Axis 2 [g] \\
\hline 95 & Peak Ground Acceleration along Vertical Axis [g] \\
\hline 96 & Maximum Horizontal Peak Ground Velocity [m/s] \\
\hline 97 & Peak Ground Velocity along Axis $1[\mathrm{~m} / \mathrm{s}]$ \\
\hline 98 & Peak Ground Velocity along Axis $2[\mathrm{~m} / \mathrm{s}]$ \\
\hline \multirow[t]{2}{*}{99} & Ground Motion Records from Recording Station \\
\hline & Credits and Comments \\
\hline $100 *$ & Full Name(s) of Person(s) Entering Information into Database \\
\hline $101 *$ & Full Name(s) of Person(s) contributing Information (Investigators) \\
\hline 102 & Investigator Organization (University, Organization, or Company) \\
\hline 103 & Reconnaissance Organization (if applicable) (e.g. EERI, ASCE, etc.) \\
\hline $104 *$ & Full Citation(s) for any Reports Used \\
\hline 105 & Comments \\
\hline
\end{tabular}

* Required field

** At least one field under this category must be provided

Table 4 Subset of the data fields defined and collected for buildings in the Chile Database. The data appears in the "essential" building data dataview with these column numbers.

\begin{tabular}{|l|l|}
\hline \multicolumn{1}{|c|}{$\begin{array}{c}\text { Column } \\
\text { Number }\end{array}$} & Data collected for buildings and presented in essential building data dataview \\
\hline 1 & Building ID \\
\hline 2 & Building Name \\
\hline 3 & Main Building Photo \\
\hline 4 & Address \\
\hline 5 & City \\
\hline 6 & Latitude \\
\hline
\end{tabular}




\begin{tabular}{|l|l|}
\hline 7 & Longitude \\
\hline 8 & Earthquake Name \\
\hline 9 & Photographs \\
\hline 10 & Stories Above Ground \\
\hline 11 & Typical Plan Shape \\
\hline 13 & General Drawings \\
\hline 14 & Closest Station ID \\
\hline 15 & Closest Station Name \\
\hline 16 & Distance to Closest Station \\
\hline 17 & Maximum Horizontal PGA \\
\hline 18 & Maximum Horizontal PGV \\
\hline 19 & Ground Motion Records from Closest Station \\
\hline 20 & Status of Building after Earthquake (Open or Closed to Public?) \\
\hline 21 & $\begin{array}{l}\text { Assigned Tag (Red -indicating danger to occupants-, Yellow, or Green -indicating no } \\
\text { danger to occupants-) }\end{array}$ \\
\hline 22 & $\begin{array}{l}\text { Answer to question “were structural failures or severe structural damage } \\
\text { documented in the available photographs?" }\end{array}$ \\
\hline 23 & Photo showing an example of what was deemed to be severe structural damage \\
\hline 24 & $\begin{array}{l}\text { Answer to question “was damage to nonstructural elements documented in the } \\
\text { available photographs?" }\end{array}$ \\
\hline 25 & $\begin{array}{l}\text { Photo showing an example of what was deemed to be damage to nonstructural } \\
\text { elements }\end{array}$ \\
\hline 26 & Sources for information about the building \\
\hline Sources of information about the damage caused by the earthquake \\
\hline
\end{tabular}

* Required field

** At least one field under this category must be provided

\section{Exploring the Building Data using Tabular Views}

The $\mathbf{2 0 1 0}$ Chile earthquake link on the NIST Disaster and Failure Studies HUB homepage takes users to the Chile earthquake database landing page shown in Figure 3. The landing page provides a summary of

The 2010 Chile Earthquake: Ground Motion and Building Performance Database

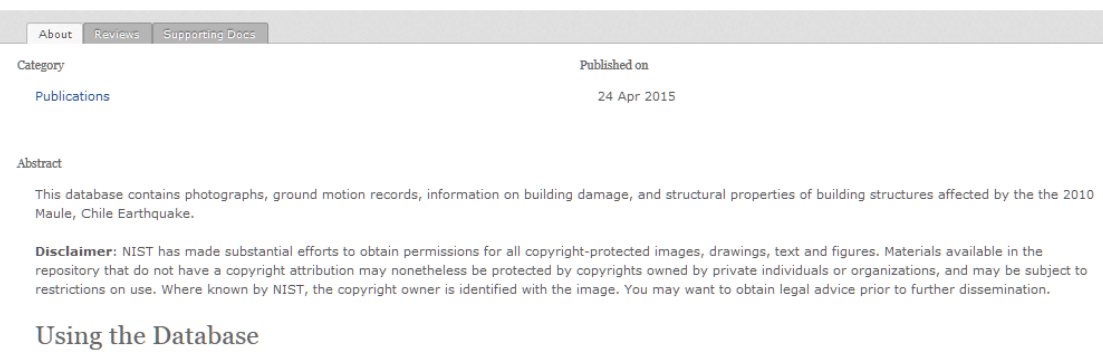

Using the Database

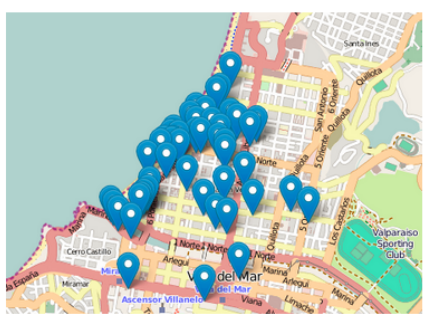

The database has nearly 100 fields, more than 22,000 photographs, and hundreds of drawings
for a total of 273 buildings. A list fof fields is provided here. The database contains information collected after the 1985 Valparaiso Earthquake and the 2010 Maule Earthquake to allow comparisons.

Exploring Data in Tabular Form There are three options or data views for exploring data:

- Full Data View displays all buildings and all fields. • Essential Data View displays a subset of fields. (those fields marked with asterisks here).

- Flexview allows users to select fields to be displayed. In the FlexView, double click on fields in the left window to select them, then click on Launch Custom View the content of the database for the 2010 Maule earthquake, as well as data from the 1985 Valparaiso earthquake, which are included in the database for comparison.

The landing page presents links to viewers for the earthquake data and includes brief instructions for using the viewers. 
At the bottom of the landing page are credits for institutions and persons who contributed data, references to sources and efforts identified in the Chile Database, and related links.

\subsection{Navigate, Search, Discover and Download Using "Dataviews"}

Tabular views called "dataviews" are used to browse, search and explore structural properties and building damage. Each row of the dataview identifies a building and presents data corresponding to that building in the columns for that row (Figure 4). Column headers label the data in each dataview column, and users can hover over or click on each header for a detailed description of the data in that column.

Tabular building data displayed in dataviews can be

- Searched in one or more columns using the column search box at the top of each column

- Searched across all columns in the tabular view using the dataview search box

- Sorted on any column in alphabetical order (for text) or numerical order (for numbers)

- Filtered from one dataview to another through column links

- Filtered by pop-up dialog box selections

- Linked to maps displayed with OpenStreetMap based on building coordinates, with markers that display data corresponding to the building

- Customized for user specified data columns

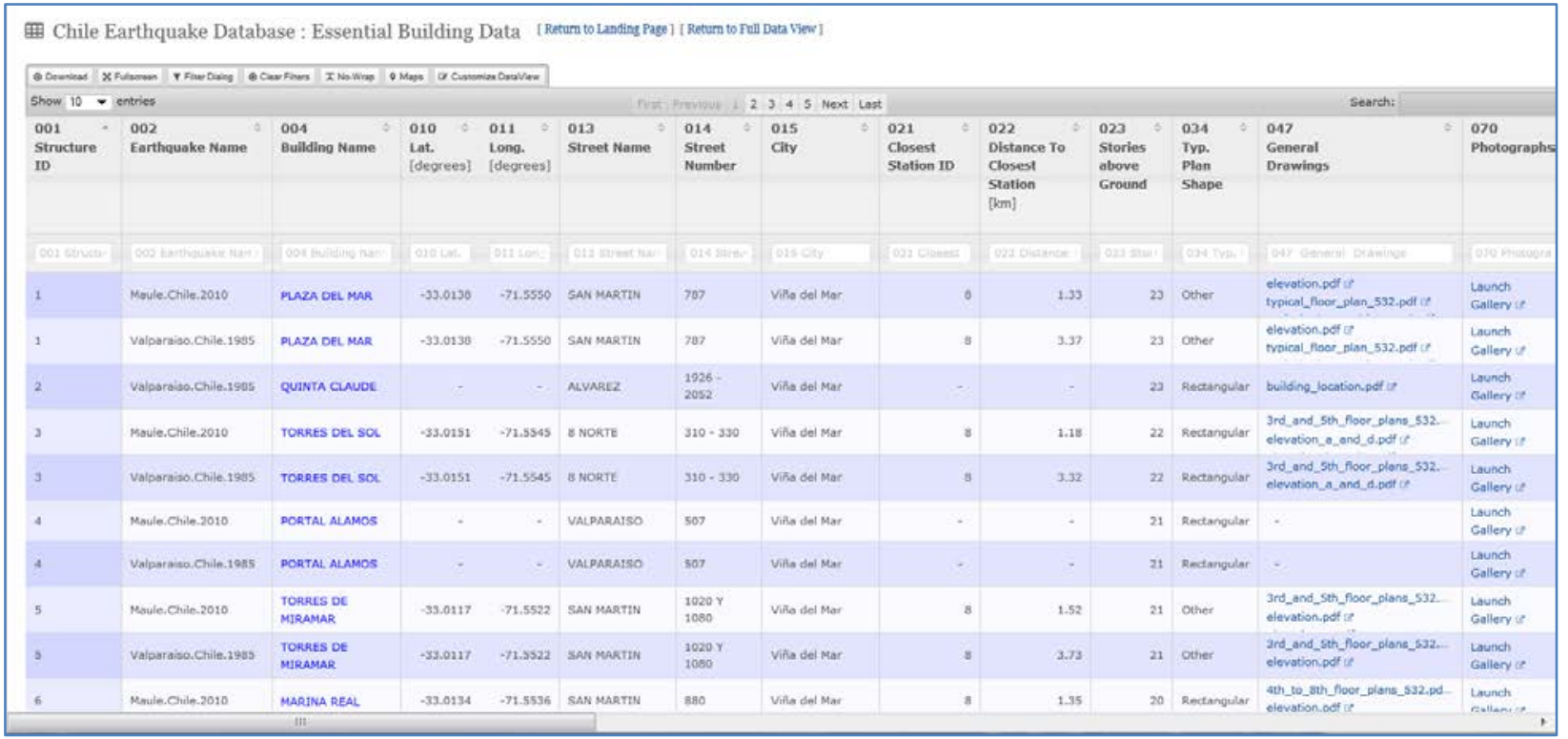

Figure 4 The "Essential Building Data" dataview displays a subset of the full set of building data collected for the Chile Database.

The operation and use of the features listed above will now be described using the "Essential Building Data" dataview shown in Figure 4, which displays damage and structural property data collected for the 273 buildings in the Chile Database. 
Navigate: Each building is assigned a Structure ID and is identified with a building name, address and coordinates (degrees latitude and longitude). Users can scroll to the right across the dataview to see all columns and can scroll to the bottom of the dataview to see all displayed rows. By default, 10 rows are displayed per dataview page. Users can page through the rows of the dataview or change the number of displayed rows to see more building rows on each page (Figure 5).

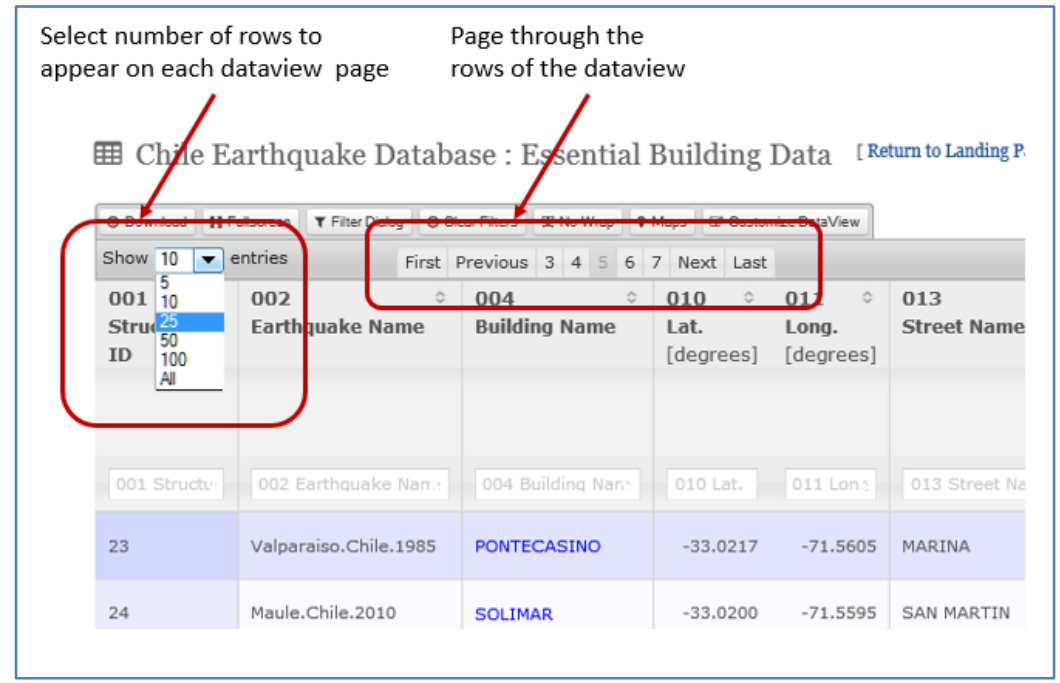

Figure 5 Viewing and navigating through the buildings in the dataview.

Search: A "search box" is available for every column of data in a dataview. Any column of text data can be searched using words or phrases entered in the column search box. Users can click on the search box to see the list of unique entries in that column, and can choose one of the entries for filtering the column. Users can also enter any phrase, word or portion of a word for searching that column, and the results of that filter will be displayed in the dataview. Users can remove search text by clicking on the " $x$ " in the column search box. Any column of numeric data can be searched by using the menu of values in the column (user selects one to filter the column) or by using comparison and range filtering such as " $>$ ", " <" and " $=$ " (Figure 6). Numeric filters can be removed using the " $x$ " in the column search box.
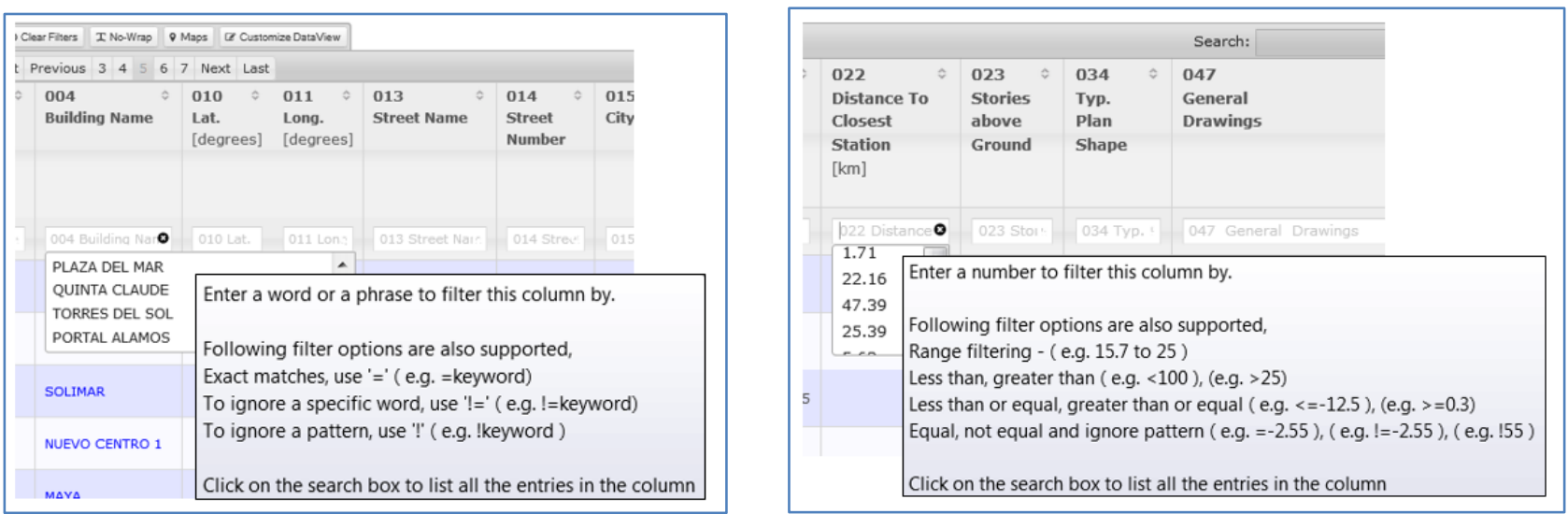

Figure 6 Options for searching and filtering columns of text (left) or numeric (right) data. 
Search filters can be used for any number of columns at the same time to discover data, and all column filters can be cleared at the same time using the Clear Filters button at the top of the dataview. Users can also search across all columns using the Search box at the top of the dataview (Figure 7).

The Filter Dialog button at the top of the dataview offers another way for users to set search filters across multiple dataview columns (Figure 8). Clicking on the button provides users with a pop-up dialog box with tabs containing categories of the dataview columns. The data fields listed in the tabs can be filtered in the same way as the column search boxes by 1) clicking for the menu of values to choose from, and 2) entering text or values for filtering.

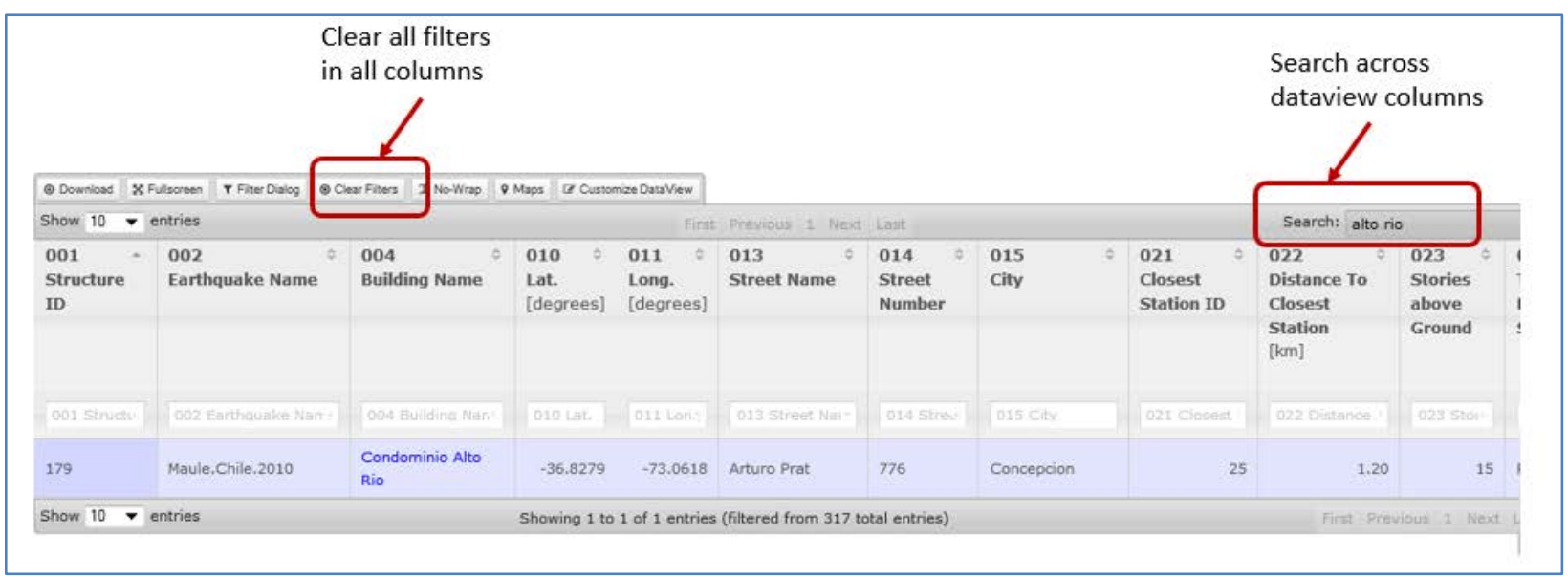

Figure 7 Clear Filters button clears all filters set on the columns of the dataview. Users can enter text for a global search across all columns of the dataview in the Search box at the top of the dataview.

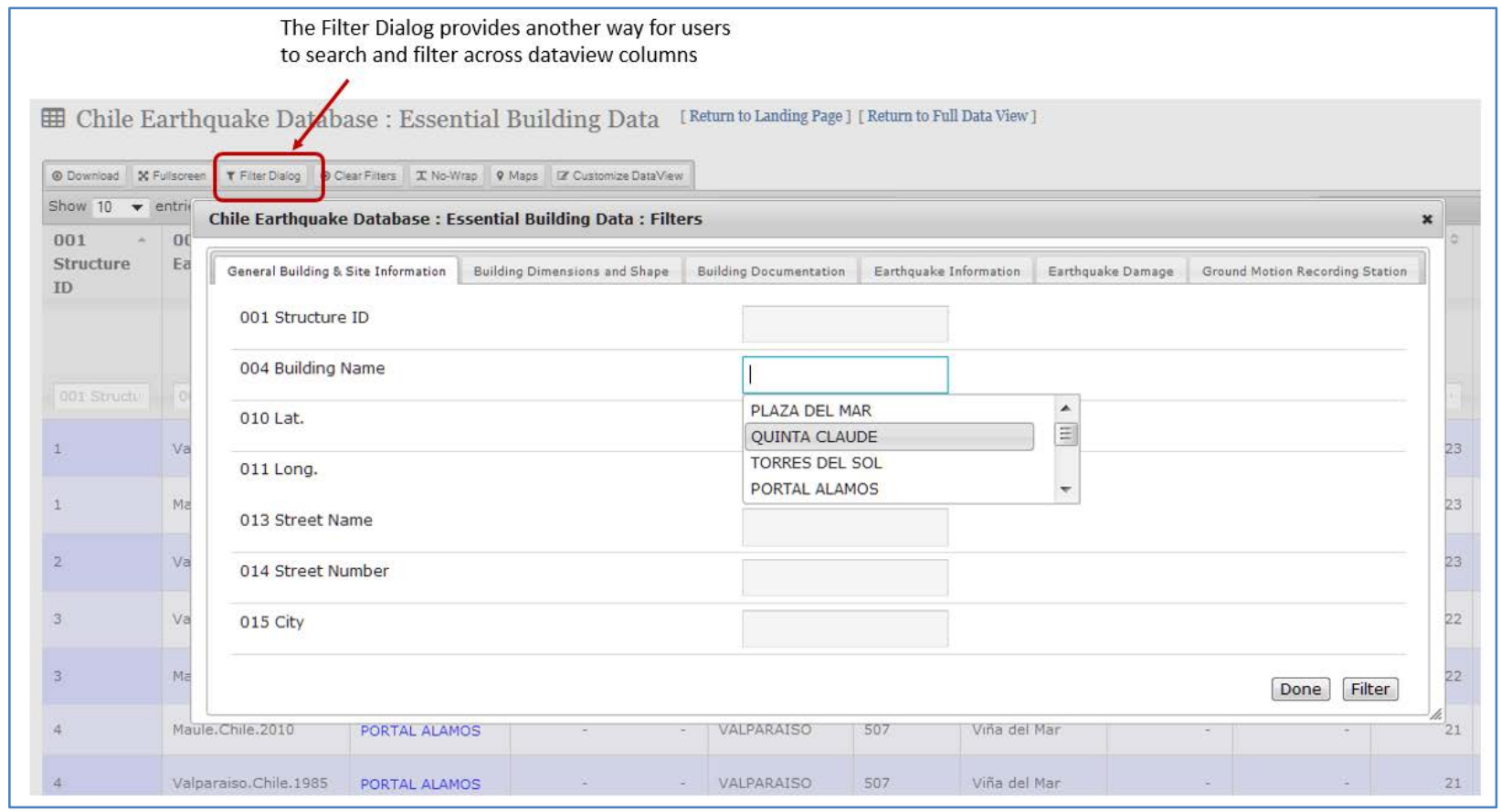

Figure 8 Using the Filter Dialog to set filters across dataview columns to browse and search essential building data. 
Sort: Columns can be sorted in ascending or descending order using the up/down arrows by the column header. Searches occur on filtered column data, and any "blank" values (represented in the dataview by a dash) are included in the sorted results.

Clickable links: Data from one dataview can link to other dataviews, to files, or to pop-up information. Figure 9 shows pop-up tabular data when users click on either of the "Torres Del Sol" Building Name links. As shown in Figure 9, thetabular data for "Torres Del Sol" building provides a side-by-side comparison of data in essential dataview for the building after the Maule and Valparaiso earthquakes. Clickable links in dataviews can bring up reconnaissance files (e.g., drawings, photos) from the repository. Clickable links can also connect users to other dataviews or to tools like the Photo Viewer described in Section 5.

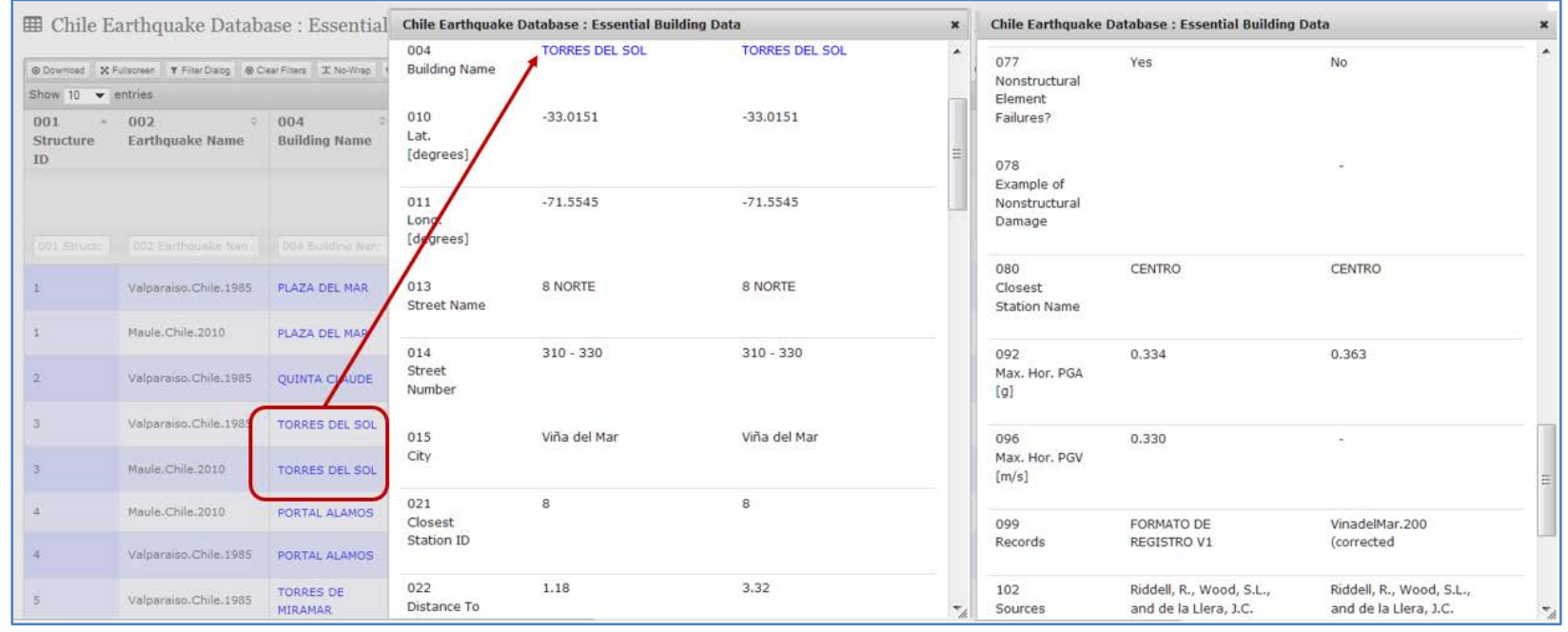

Figure 9 Clickable links in the Building Name column let users compare data from the Maule and Valparaiso earthquakes.

Download: Data can be downloaded as a spreadsheet (CSV format, comma delimited) from any dataview, either before or after filtering. When data is filtered, only the filtered results are exported. Users can click the Download button at the top of the dataview to export the dataview to a spreadsheet (Figure 10).

Users can also download any photograph or file (PDF, XLS, Text and other formats) displayed and linked from the dataview. For photographs, each downloaded image filename incorporates the photographer's name for attribution and is transferred in full resolution. Users can also download drawings and other

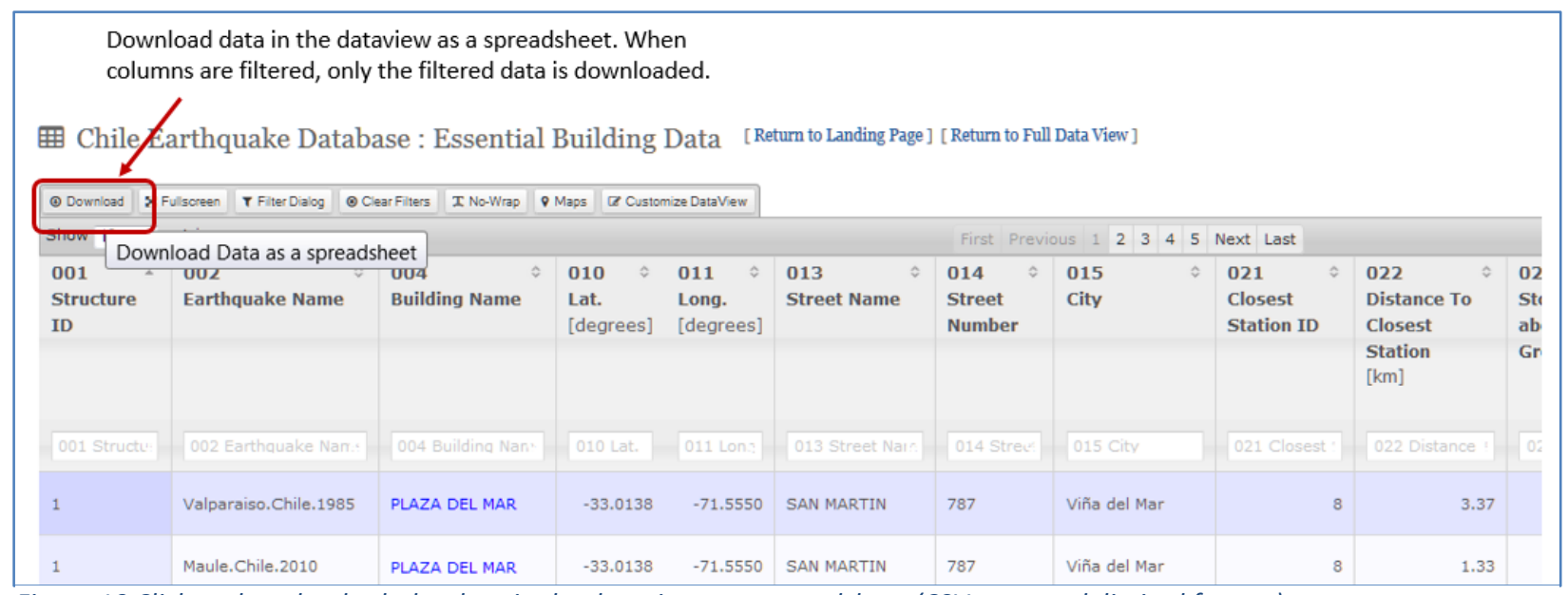

Figure 10 Click to download tabular data in the dataview as a spreadsheet (CSV comma delimited format). 
data files that are presented and linked in dataviews.

\subsection{Maps with “Dataviews"}

Users can click on the Maps button at the top of the dataview to bring up a display of markers showing the map location of all buildings in the current dataview (i.e., those with latitude and longitude) using OpenStreetMap https://www.openstreetmap.org/. If the dataview has been filtered, only the filtered building location results are shown on the map. Each marker presents data about the building, including building name, address, structural characteristics and damage (Figure 11).

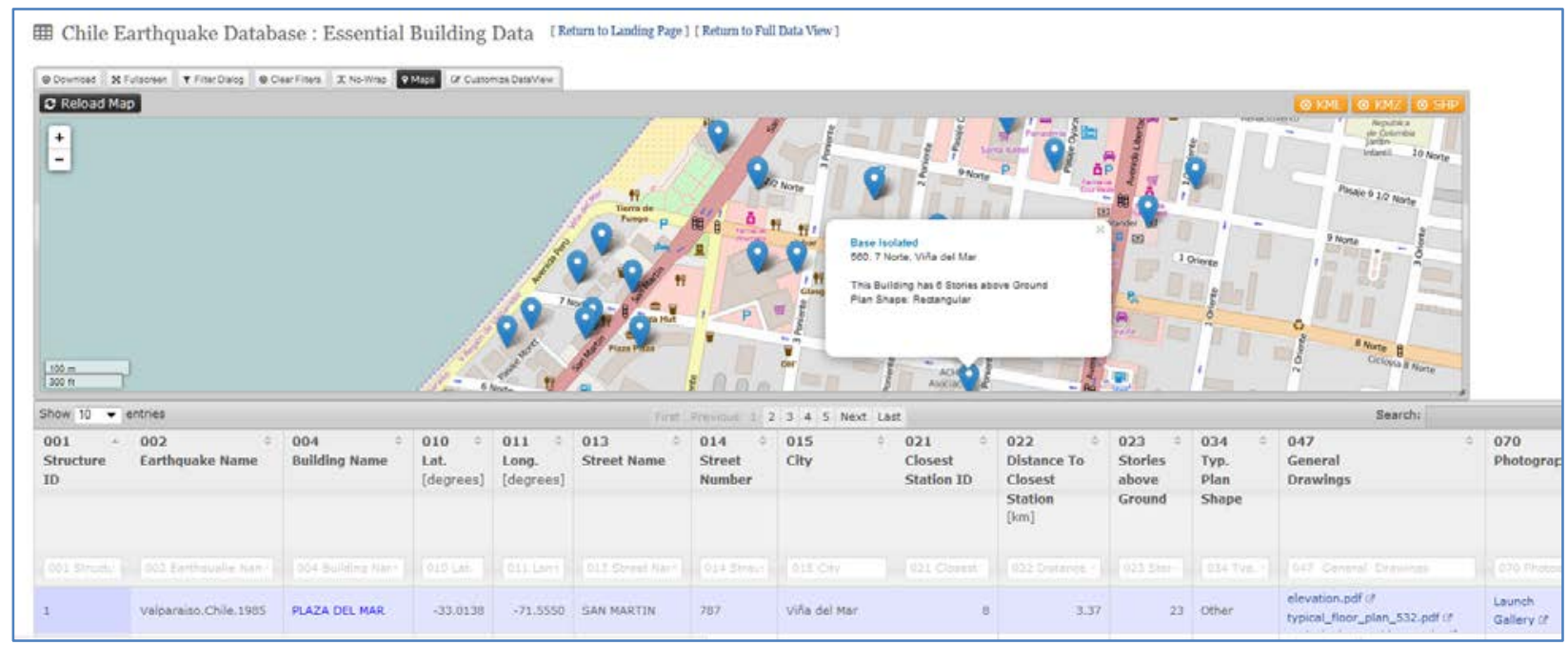

Figure 11 Dataview maps display markers for buildings in the dataview.

(C) OpenStreetMap contributors

Subject to the Open Database License (www.openstreetmap.org/copyright) users can download map data in the following formats:

- KML format

- $\mathrm{KMZ}$ format

- SHP format (for ESRI compatibility)

\subsection{The Buildings Dataviews}

Two dataviews are available for search and discovery of data collected for buildings in the Chile Database:

Full Building Data: This dataview presents all information collected for the 273 buildings in the Chile Earthquake Database. Of these, 179 were surveyed in 1985 (De La Llera et al.) and 131 were surveyed in 2010. There are 108 data elements defined for buildings in the database, encompassing structural characteristics and earthquake damage. All 108 data elements are presented as columns in the full dataview, though many of these are blank for most buildings.

This dataview can be used to browse, search and compare all tabular data collected for the 273 buildings. In addition, for each building, there are columns in the Full Building Data dataview that display links to repository files corresponding to that building (drawings, reports, etc.) and a column with a link to the Photo Viewer where reconnaissance photographs for that building can be browsed and searched. The Photo Viewer is described in Section 5. 
Essential Building Data: This dataview presents a subset of the full data collected for the 273 buildings. The subset of data elements was chosen to include information that was available for most buildings. This view also contains links to repository files and a link to the Photo Viewer.

Additional notes about data and files that are available for some of the buildings in the Full Building Data and Essential Building Data dataviews follow:

1. Structural drawings, structural analysis models: Detailed drawings were obtained for 14 structures. General drawings showing the layout of structural walls and essential dimensions were obtained for 121 structures. Input files for numerical simulation were obtained for 6 structures.

2. Photos of impacted buildings including descriptions: 22,474 photographs were collected, classified, and tagged for the Chile Database repository. Images from the Maule earthquake show details of damaged buildings and buildings not damaged.

3. Mapped structural damage: Detailed maps describing structural damage were obtained for six buildings.

4. Instrumented building response data: No data from instrumented buildings were obtained.

5. Geotechnical information: Soils reports were obtained for five buildings.

6. Building specific literature: Forensic reports were obtained for two buildings.

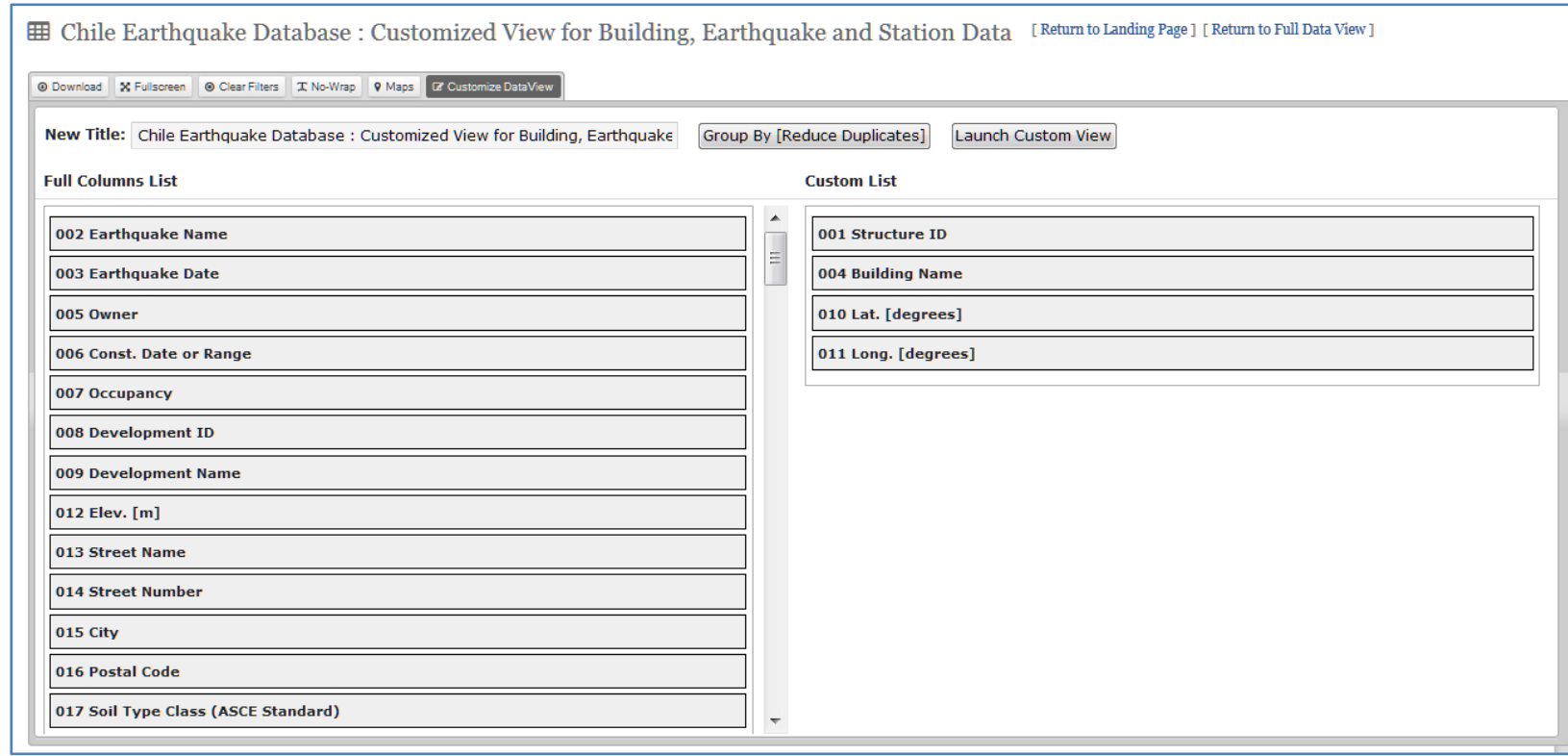

Figure 12 The Flex View lets users customize their dataviews by selecting the columns they want to search and explore.

Because the building dataviews have a very large number of columns (in particular the Full Building Data dataview), the FlexView feature is provided so that users can customize a dataview to contain only the columns they want to explore. Users can choose the FlexView link on the Chile Database landing page or click the Customize button at the top of any dataview. By using the interface shown in Figure 12, users 
can select which columns to include in their dataview and then click on the Launch Custom View button to build a custom dataview.

To build the custom dataview, users double-click the columns from the full list of columns in the left panel of the FlexView interface to select and move columns to the right panel, where they will become part of the custom dataview. The web address URL of the generated dataview can be bookmarked and kept for future use - and users can make the link available to other users via email or by adding it to documents.

\section{Exploring Photographs}

\subsection{Using the Photo Viewer}

The majority of data files contributed to the Chile Database repository are the 22,474 photograph files. To make this information accessible and usable, each photograph is tagged with metadata that can be used for search and discovery through the Photo Viewer (Figure 13).

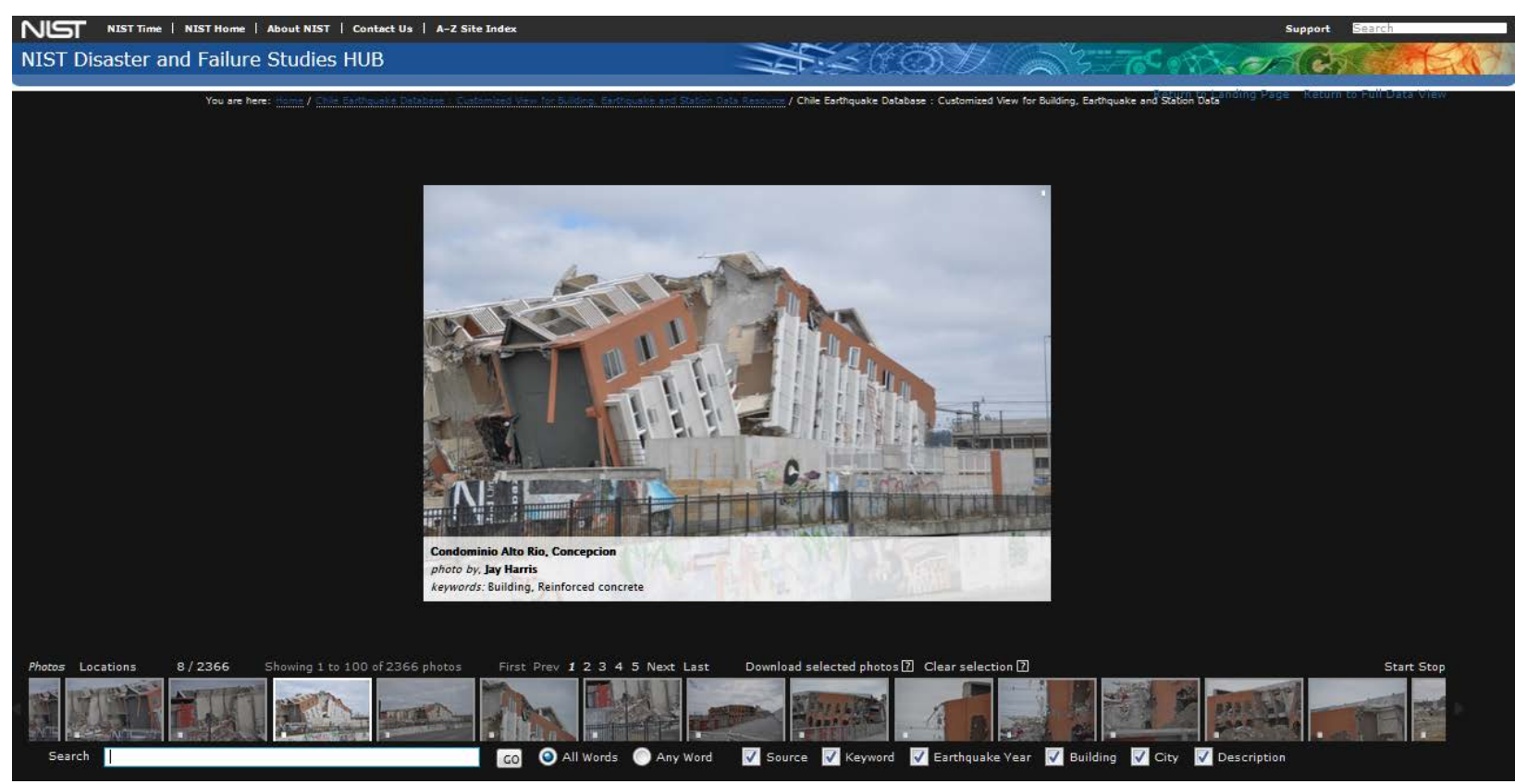

Figure 13 The Photo Viewer for search and discovery of reconnaissance photographs stored in the Chile Database repository.

Tagging information consists of:

- Keywords. A collection of 23 keywords was used to tag the photographs in the repository. These keywords are listed in Table 1 in Section 3. As photographs were uploaded to the repository, keywords were attached as metadata to be used by the Photo Viewer for searching. The keyword tags were also inserted into the headers of the photograph files so they would be available to users when photos are downloaded through the dataviews or through the Photo Viewer.

- Photographer. The name of the photographer was attached as metadata to each photograph uploaded to the repository, and this tag can be used for searching photos in the Photo Viewer. The 
header of each image file was modified to include the name of photographer, and the name of the photographer is appended to the name of each downloaded image file.

- Location: The photograph is tagged with information about the building shown in the photograph including building name, address, and coordinates. These tags can be used for searching in the Photo Viewer.

- Earthquake: The name and date of the earthquake (Maule 2010 or Valparaiso 1985) are attached to the photograph as metadata and can be used for Photo Viewer searching.

To ensure appropriate use of downloaded photos, the header of each photograph file was modified during upload to include not only the assigned keywords and name of the photographer, but also the building name, address, coordinates, earthquake name and date. Users can access or edit the photo header with any standard file browser after download.

The Photo Viewer lets users page through photos stored in the Chile Database repository. A thumbnail filmstrip of photos is shown as the user navigates through the images. Users can click on any thumbnail in the filmstrip to display that image as the main Photo Viewer photograph.

Users can also click on the main photograph to view the image enlarged to its original size. When users hover over the main displayed photo, metadata tags are shown as an overlay (keywords, photographer name, location, and earthquake).

Searchable tags for the Photo Viewer include

- Keywords

- Source (name of the photographer)

- Building (name of the building shown in the photograph)

- City (location of building shown in the photograph)

- Earthquake year $(2010,1985)$

- Description (text associated with the photo by the uploader)

In the Photo Viewer search box (located at the bottom left of the Photo Viewer), users can search for photos associated with single words (e.g. tie), concatenated strings identified with quotation marks (e.g. "bar buckling"), and groups of words and concatenated strings (e.g. "bar buckling" tie Jay Harris). User can request that the search use "All Words" or "Any Word" (Figure 14).

Maps are available at the Locations link in the Photo Viewer. Users can click to switch between the Photos and the Locations views. The Locations view displays markers on an OpenStreetMap map for the building locations of the currently selected photographs. The map automatically zooms and pans to show markers identifying buildings and locations where the photo was taken. If the user chooses a specific photo (by clicking on it in the thumbnail filmstrip) its marker on the map is animated to show where that photo was taken in relation to the building locations, using the photos GPS coordinates. Note that not all photos have GPS coordinates to allow their mapping.

Users can select and download any number of photographs at a time as a zip file using the Photo Viewer. After completing a photo search, users can select from the resulting image files by clicking the 
checkbox for photos of interest and then clicking the link to Download selected photos. Photos will be downloaded to folders that reflect the hierarchical ordering for 1) earthquake, 2) building and 3) source. Users can right-click on downloaded photos for additional information.
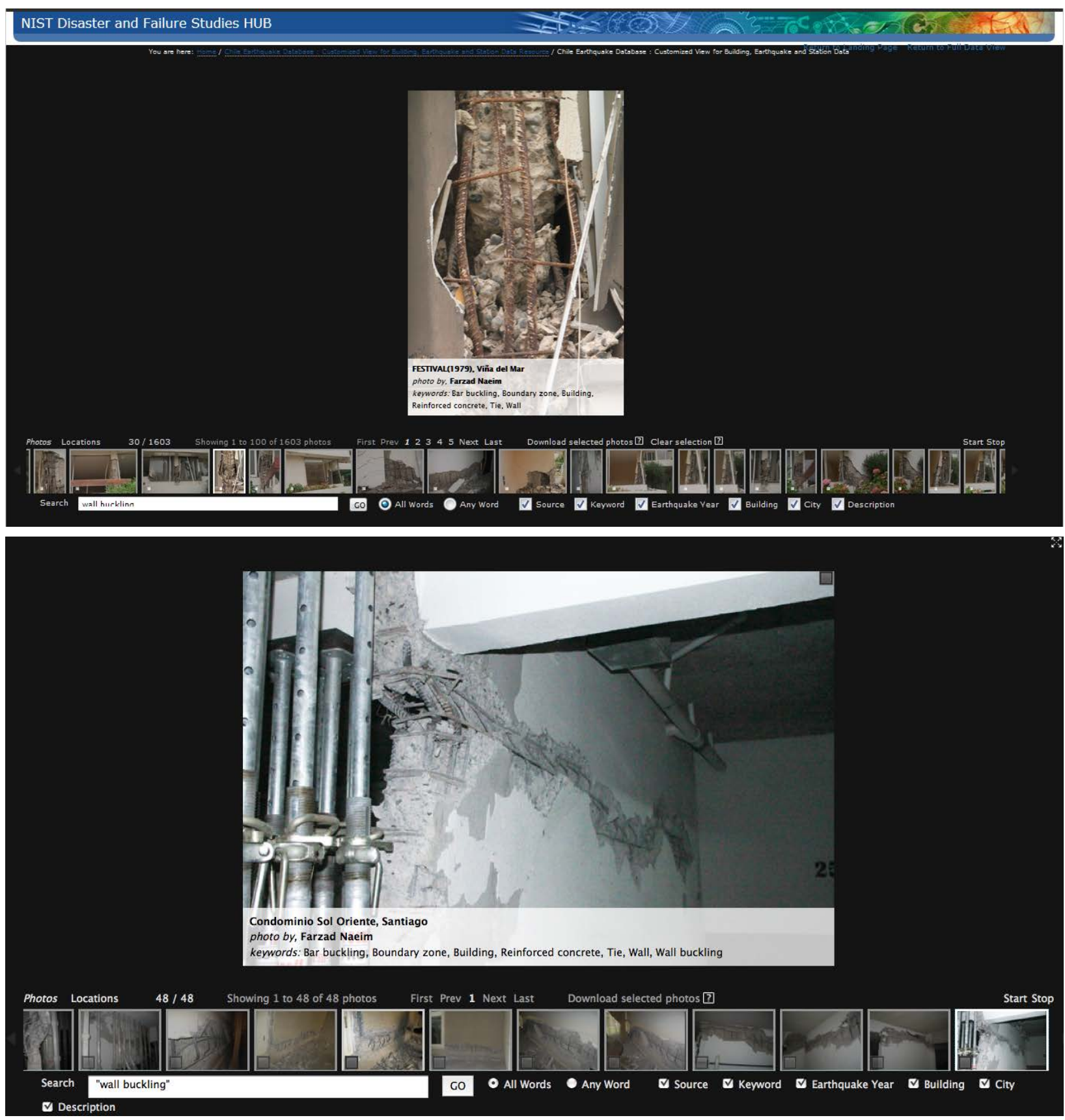

Figure 14 Users can enter wall buckling and choose Any Word to search for all photos with wall or bucking (top). Users can enter either "wall buckling" or wall bucking with All Words to search for all photos with both wall and buckling (bottom).

The Photo Viewer can also be launched for any building from the building dataviews. When launched for a specific building, only photos tagged with that building appear for searching in the Photo Viewer filmstrip of thumbnail photos. 


\subsection{Connecting Photographs and Drawings}

After the Maule earthquake, buildings 179, 182, 184, 185, 203, 205, and 271 were inspected in detail by a team led by F. Medina and J. Moehle. The team created drawings with labels identifying locations where photos were taken. Those drawings appear in column 069 (General Files) of the building dataviews. Audio recordings describing damage and identifying surveyed locations are also available in column 069. Files in column 069 are described in text files named "ReadMe.txt", also included in column 069.

To search for photos taken at a given location on a drawing, go to the Photo Viewer search box and enter the label identifying the location of interest from the drawing. The drawing label consists of an abbreviation for the location followed by the building story and location in the drawing. For instance, entering PR-01-022 in the Photo Viewer search box gives the user photos taken at location 022 in story 01 of building PR (Plaza del Rio). To get results for this type of search, the "keyword" box must be checked before searching. Note that the drawing showing location 022 in story 01 is available in column 069 with the name PR-01 (PRfieldwork, PRsurvey, PR-01).dwg. In drawing names, the first two letters (PR) identify the building and the digits after the hyphen identify the story (01).

\section{Other Chile Earthquake Data}

\subsection{Ground Motion Data}

Ground motion data in the Chile Database consist of

- Records from 28 stations (21 maintained by the Civil Engineering Department and 7 maintained by the Seismology Department of the University of Chile) triggered by the earthquake of 2010

- Records from 26 stations (obtained from COSMOS) triggered by the earthquake of 1985

For each ground motion record, the following information was collected for the database and is listed in the strong motion dataview:

- Name (assigned by network manager)

- Code (assigned by network manager)

- Location (city where the station was located)

- Coordinates of the stations

- Name of Network Manager at time of earthquake

- Type of Structure (in which the station was located)

- Location of Station within Structure (typically ground level or basement)

- Type of Instrument (model and manufacturer)

- Site Description

- Orientation

- Reported values for PGA and PGV (in each direction and maxima)

See Table 2 in Section 3 for more details about ground motion data.

To browse or download ground motion information related to a specific building, users should go to columns 080-099 in the Full Building Data or Essential Building Data dataviews for their building of interest. 
To explore all available ground motion data (Figure 15)., users can click on the Stations Information View link on the Chile Database landing page in the section Ground Motion Information To map stations, click on the Map button to the left of the dataview title. Click on markers identifying stations for information

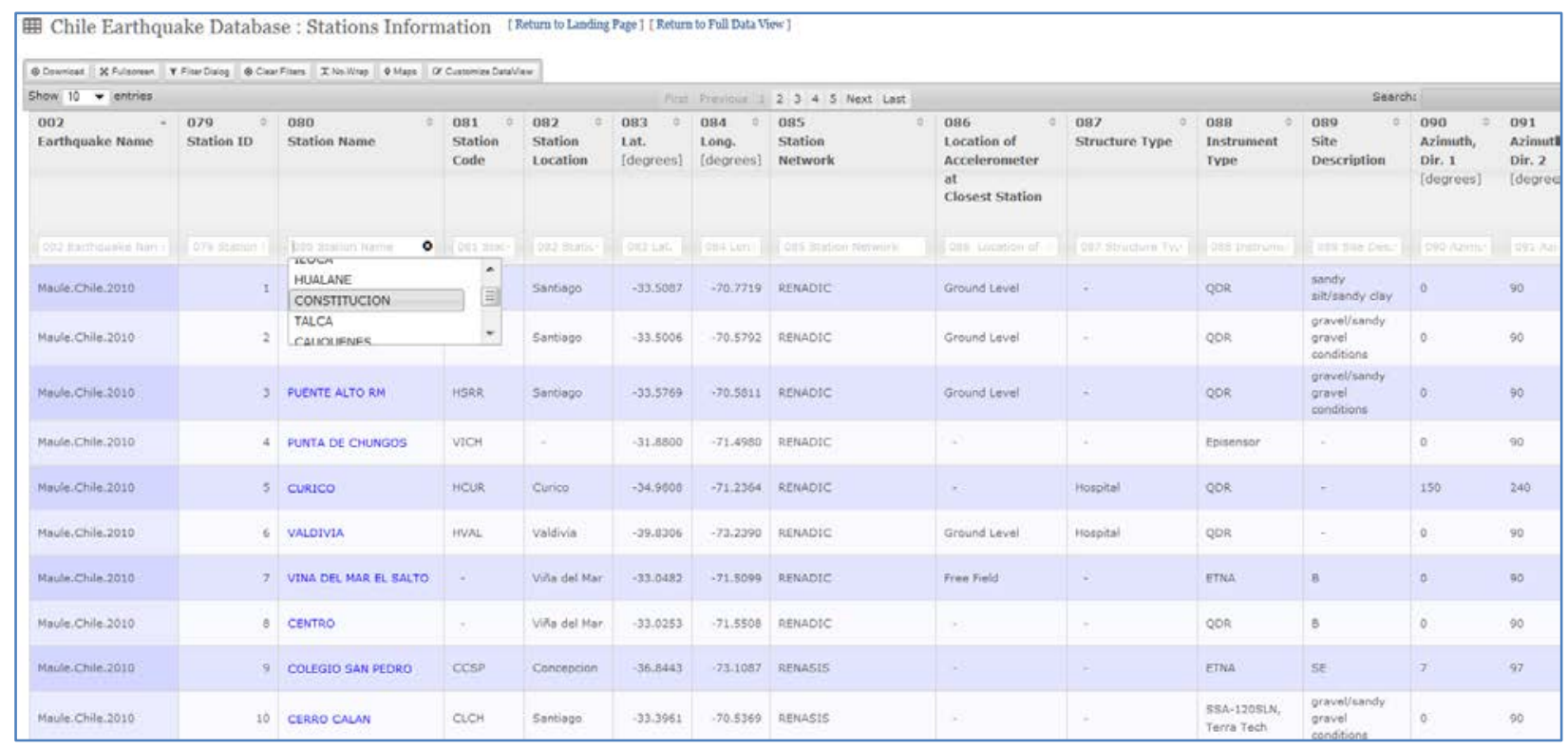

Figure 15 Dataview presenting data for all stations for both earthquakes.

about the station.

\subsection{Analysis Files}

For selected buildings, input files for numerical analysis are provided in column 072 of the Full Building Data dataview. The column header is Input Files for Structural Analysis Software, and the ReadMe file included in that column offers information on the analysis files. Clicking to sort column 072 lets users see which buildings have analysis files associated with them.

\section{Data Preservation, Longevity and the HUBzero Technology}

Data preservation addresses the long-term storage, accessibility, retrieval, and navigation of data in the Chile Earthquake Database and its associated repository of data files. The expression "long-term" refers to a period of time that is long enough to continue providing service to an interested user community through changes in hardware, software and other technologies that affect the infrastructure used to build and support the database. The data preservation plan involves two principal components: 1) HUBzero, which is used as the collaborative platform for the database, and 2) the "database technology" which is used to populate the database and support the retrieval and navigation of data. 
The longevity of the HUBzero platform https://hubzero.org is a critical element for preservation of the database and user interface built to store and access the Chile earthquake data. The HUBzero platform grew out of the NSF-funded Network for Computational Nanotechnology and was developed at Purdue University to support their nanoHUB web site at https://nanoHUB.org. Work on the "hub" infrastructure for nanoHUB began in 2002, and the success of this infrastructure as a collaborative platform led to the development of hubs for other scientific and medical research communities. These include pharmaceutical manufacturing, cancer research, molecular sciences, civil engineering, high throughput computing, and medication safety.

There are now more than 60 "science gateway" web sites (or hubs), and these web sites served more than $1,800,000$ unique visitors in 2014. HUBzero has a professional, experienced and dedicated development team at Purdue University. Each hub is supported by its own funding sources. An example is NEEShub, the earthquake engineering and simulation hub at https://nees.org, which was built and supported by a 5 year $\$ 105$ Million grant from NSF. The HUBzero team continues to maintain and advance the infrastructure, addressing data security, backup, and integrity as an integral part of Hub maintenance.

The database technology used to create the Chile Earthquake Database and repository was established in 2009 as Hub-based components for the Cancer Care Engineering project at cceHUB https://ccehub.org. The project required database technology to collect, explore and analyze patient clinical data and to annotate and track laboratory samples. The database technology was generalized and advanced from the initial implementation, and has now been used to build 80 medical and scientific research databases across 10 hubs. More than $\$ 14$ Million in funding has been dedicated to the support of research projects using this technology, including the development of new features and functions for data contribution, processing, storage, navigation, and visualization. The database technology is robust, providing effective and efficient retrieval operations from databases with hundreds of millions of records. The hub database group continues to advance and refine modes of data ingestion and data exploration, and the technology continues to maintain backward compatibility for existing databases.

Data files collected for the Chile Database consist of photos, documents, diagrams, and other files which are uploaded to the hub for inclusion in the database repository. Uploaded files are stored in a "collaborative data space", where the database system accesses them for metadata processing and repository archiving. Because uploaded files are modified for inclusion in the repository (e.g., metadata from the database is inserted into photograph headers), persistence requires preservation of the original form of the data, and effectively maintaining immutable versions of each file in the collection. To support persistence, uploaded data collections are also maintained unchanged so that the original versions of the uploaded data can be restored for access through hub administrative requests. 